in vivo $34: 3483-3487(2020)$

doi: $10.21873 /$ invivo. 12188

\title{
Implications of Topoisomerase (TOP1 and TOP2 $\alpha$ ) Expression in Patients With Breast Cancer
}

\author{
MISATO OGINO ${ }^{1,2,3}$, TAKAAKI FUJII ${ }^{1,2}$, YUKO NAKAZAWA $^{1,2}$, TORU HIGUCHI $^{4}$, \\ YUKIO KOIBUCHI $^{3}$, TETSUNARI OYAMA ${ }^{5}$, JUN HORIGUCHI ${ }^{6}$ and KEN SHIRABE ${ }^{2}$ \\ ${ }^{1}$ Division of Breast and Endocrine Surgery, ${ }^{2}$ Department of General Surgical Science, \\ Graduate School of Medicine, Gunma University, Gunma, Japan; \\ ${ }^{3}$ Department of Breast and Endocrine Surgery, National Hospital Organization \\ Takasaki General Medical Center, Gunma, Japan; \\ ${ }^{4}$ Department of Breast Surgery, Japanese Red Cross Saitama Hospital, Saitama, Japan; \\ ${ }^{5}$ Department of Diagnostic Pathology, Gunma University, Gunma, Japan; \\ ${ }^{6}$ Department of Breast Surgery, International University of Health and Welfare, Chiba, Japan
}

\begin{abstract}
Background/Aim: We evaluated the usefulness of topoisomerases (TOPs) expression as prognostic predictors in breast cancer. Patients and Methods: We retrospectively investigated sixty cases with primary breast cancer. We evaluated the tumor and non-tumor mRNA levels of TOP1 and TOP $2 \alpha$ using quantitative reverse-transcription polymerase chain reaction. TOP1/TOP $2 \alpha$ positivity was defined as the ratio of the $m R N A$ expression of cancer/normal tissue of $>1$ for both TOP1 and TOP $2 \alpha$. Results: TOP1 and TOP $2 \alpha$ were markedly overexpressed in breast cancer tissues compared to normal breast tissues. Of the 60 cases, $46(76.7 \%)$ were positive for TOP $1 /$ TOP $2 \alpha$. The relapse-free survival was relatively shorter for patients with positive TOP1/TOP $2 \alpha$. There was no recurrent disease among the 14 patients who were negative for TOP $1 / T O P 2 \alpha$, whereas four of the 46 TOP1/TOP $2 \alpha$-positive patients had disease recurrence. Conclusion: Negative TOP1 or TOP $2 \alpha$ expression may be useful for predicting better prognoses in breast cancer patients.
\end{abstract}

Breast cancer (BC) is the most common cancer in women and it is a leading cause of mortality worldwide $(1,2)$. BC is a heterogenous group of tumors with large variations in

This article is freely accessible online.

Correspondence to: Takaaki Fujii, MD, Ph.D., FACS, Department of General Surgical Science, Graduate School of Medicine, Gunma University, 3-39-22 Showa-machi, Maebashi, Gunma 371-8511, Japan. Tel: +81 0272208224, Fax: +81 0272208230, e-mail: ftakaaki@gunma-u.ac.jp

Key Words: Topoisomerase I, topoisomerase II alpha, breast cancer. prognosis and sensitivity to treatments $(3,4)$. Identification of additional biomarkers is needed to stratify BC for individualized treatment. The topoisomerases (TOP) are able to change DNA topology to facilitate replication and transcription (5-7). There are two types of TOPs: topoisomerase I (TOP1) and topoisomerase II (TOP2), classified according to their ability to make transient singleor double-stranded breaks in DNA (5-8). TOPs play key rolse in DNA function and are potential targets for cancer therapy. Several TOP inhibitors are used in clinical setting $(8,9)$. For example, TOP2 alpha (TOP $2 \alpha)$ is a molecular target of anthracycline, which is one of the key drugs in $\mathrm{BC}$ therapy $(3,10-15)$. Although TOP1 and TOP $2 \alpha$ have been reported to play key roles in tumor progression in various types of cancer (8), the clinicopathological features and significance of TOP1 and TOP $2 \alpha$ in BC have not been well elucidated. In this study, we investigated the correlations between the expression of TOP 1 and TOP $2 \alpha$ and the clinicopathological features of cases with $\mathrm{BC}$, and we evaluated the usefulness of their expression for the prognosis of $\mathrm{BC}$, focusing on the differential expression between cancer tissue and non-cancerous tissue.

\section{Patients and Methods}

We retrospectively investigated sixty cases with primary $\mathrm{BC}$ who had undergone radical breast surgery. Breast cancer tissue and paired normal tissue were obtained at the Division of Breast and Endocrine Surgery, Gunma University between March 2009 and January 2012. Cases who received neoadjuvant chemotherapy, cases with synchronous bilateral breast cancer, male cases, and cases with incomplete clinical information were excluded. Written informed consent was obtained from all cases for the use of their records, samples and images in future studies, and this was approved by the Clinical Ethics Committee of Gunma University. 
The patient's age, histology, size of invasive primary tumor, lymphatic (ly) or vascular invasion (v), nuclear grade, estrogen receptor (ER) and progesterone receptor (PgR) expression status, human epidermal growth factor receptor 2 (HER2) score of the primary tumor, axillary lymph node status, and the use of adjuvant chemotherapy or hormone-therapy were extracted from the database. The ER and PgR statuses and the HER2 scores of the primary tumors were assessed as previously described (16). We evaluated the tumor and non-tumor mRNA levels of TOP1 and TOP $2 \alpha$ using quantitative reverse-transcription polymerase chain reaction (RT-qPCR) (17).

Analysis of $m R N A$ expression. Immediately after breast surgery, breast cancer tissue and paired normal breast tissue were obtained for RNA extraction. RNA was isolated from the tumor tissue and non-tumorous tissue separately. cDNA was prepared using the High Capacity Reverse Transcription kit (Life Technologies, Carlsbad, CA, USA) according to the manufacturer's instructions. The TOP1 and TOP $2 \alpha$ expression levels were determined by TaqMan real-time PCR (TaqMan array card; Life Technologies) after TaqMan assaybased pre-amplification, as described (17). Beta-actin was used as an internal control for normalization. The gene expression levels are expressed as ratios (i.e., the differences between the $\mathrm{Ct}$ values) between the target gene and the control gene.

The assay IDs used in this study are as follows. TOP1 (mRNA: TOPOI, assay ID: Hs0023259_m1, gene symbol: TOP1, gene name: DNA topoisomerase I) and TOP2 $\alpha$ (mRNA: TOPOII, assay ID: Hs003573333_g1, gene symbol: TOP2 $\alpha$, gene name: DNA topoisomerase II alpha). We calculated the TOP1 and TOP $2 \alpha$ expression ratios of paired cancer tissue and non-cancerous tissue. Samples were TOP1/TOP $2 \alpha$ positive when the ratio of mRNA expression in cancer vs. normal tissue was $>1$ for both TOP1 and TOP $2 \alpha$. The samples were negative for TOP $1 /$ TOP $2 \alpha$ when either TOP1 or TOP $2 \alpha$ was negative.

Statistical analysis. In order to examine whether the clinicopathological features associated with the TOP $1 / \mathrm{TOP} 2 \alpha$ expression, we divided the $\mathrm{BC}$ cases into two groups based on the positive/negative TOP1/TOP $2 \alpha$ status. We performed a univariate statistical analysis using the $\chi^{2}$ test with Yates' correction or Fisher's exact test. Student's $t$-test was used for comparisons of the two groups. For the correlation between TOP $1 /$ TOP $2 \alpha$ status and prognosis, Kaplan-Meier curves of disease-free survival (DFS) were drawn using the log-rank test. DFS was defined from the day of surgery to the day of initial locoregional and/or distant BC recurrence in the follow up term. A difference with a $p$-value $<0.05$ was considered significant.

\section{Results}

In total, 60 cases with paired cancer and normal tissue were included in the analysis. The expression levels of TOP1 and TOP $2 \alpha$ in cancer and non-cancerous tissues are shown in Figure 1. TOP1 and TOP $2 \alpha$ were both markedly overexpressed in the cancerous tissue compared to the noncancerous tissue in cases with $\mathrm{BC}$. The characteristics of the two patient groups based on positive/negative TOP1/TOP $2 \alpha$ status are summarized in Table I, which also provides the results of the univariate analysis conducted to investigate the
Table I. Clinicopathological features associated with relative expression of TOP $1 / T O P 2 \alpha$.

\begin{tabular}{lccc}
\hline & $\begin{array}{c}\text { TOP1/TOPO2 } \alpha \\
\text { negative } \\
(\mathrm{n}=14)\end{array}$ & $\begin{array}{c}\text { TOP1/TOP2 } \alpha \\
\text { positive } \\
(\mathrm{n}=46)\end{array}$ & $p$-Value \\
\hline Age (y.o., median) & $64(30-87)$ & $59(37-87)$ & 0.534 \\
Histology (n) & 11 & 38 & 0.623 \\
$\quad$ Invasive ductal carcinoma & 2 & 3 & \\
Invasive lobular carcinoma & 1 & 5 & \\
Others & $2.5 \pm 0.9$ & $2.7 \pm 2.1$ & 0.716 \\
Tumor size $( \pm$ SD) (mm) & 4 & 21 & 0.206 \\
Lymph node metastasis (n) & 12 & 37 & 0.498 \\
ER positive (n) & 12 & 33 & 0.247 \\
PgR positive (n) & 3 & 5 & 0.272 \\
HER2 positive (n) & 6 & 24 & 0.381 \\
Nuclear grade 3 (n) & 9 & 36 & 0.918 \\
ly positive (n) & 1 & 13 & 0.096 \\
v positive (n) & 5 & 21 & 0.367 \\
Adjuvant chemotherapy & 11 & 35 & 0.580 \\
Adjuvant hormonetherapy & & & \\
\hline
\end{tabular}

TOP: Topoisomerase; n: number; ER: estrogen receptor; PgR: progesterone receptor; HER2: human epidermal growth factor receptor 2; ly: lymphatic invasion; v: vascular invasion.

relationships between TOP1/TOP $2 \alpha$ expression and various clinicopathologic variables.

Of the 60 eligible patients, $46(76.7 \%)$ had positive TOP1 and TOP $2 \alpha$ expressions; i.e., both TOP 1 and TOP $2 \alpha$ mRNA expression levels in cancer tissue were higher than those in normal tissue. There was no significant correlation between positive TOP1/TOP $2 \alpha$ status and any of the patients' clinicopathological variables. The Kaplan-Meier curves showed that the DFS was relatively shorter for the cases with positive TOP1/TOP $2 \alpha$, but there was no significant difference $(p=0.276)$ (Figure 2$)$. The overall median followup period was 73.1 months (range $=3.2-90.0$ months). There was no recurrent disease among the 14 patients with negative TOP1/TOP $2 \alpha$, whereas of the 46 patients with positive TOP1/TOP2, four patients had disease recurrence. It is interesting that the negative TOP $1 / \mathrm{TOP} 2 \alpha$ patients had no recurrent disease although the differences were not significant in any clinicopathological features between positive and negative TOP $1 / \mathrm{TOP} 2 \alpha$ cases.

\section{Discussion}

Topoisomerases (TOP1 and TOP $2 \alpha$ ) are potential targets for cancer treatment. TOP 1 and TOP $2 \alpha$ are expressed in various tumors, including breast cancer (6). Several studies have reported that TOP 1 and TOP $2 \alpha$ are tumor drivers in various cancers (8). The key observations obtained in the present study were as follows: 1 ) TOP1/TOP $2 \alpha$ expression was not 


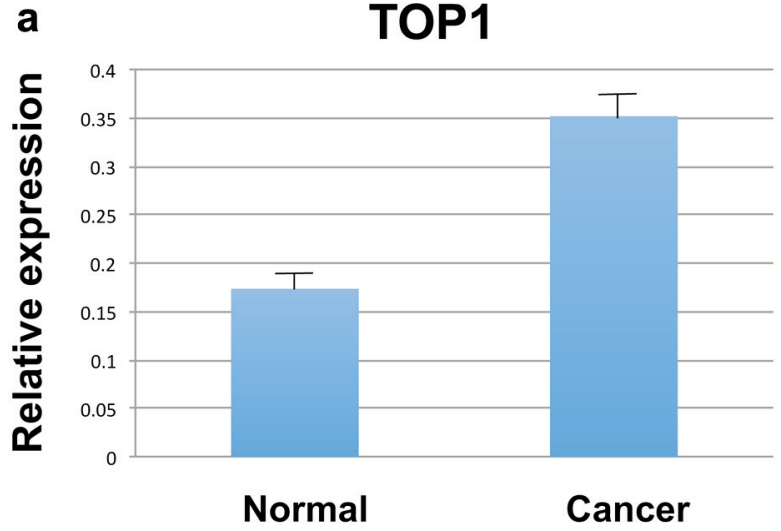

b

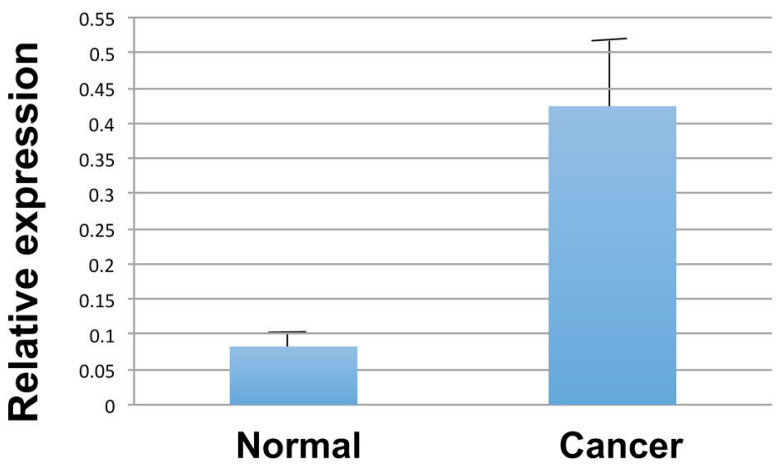

Figure 1. The expression levels of TOP1 and TOP $2 \alpha$ in cancer and noncancerous tissue are shown. (a) TOP1 and (b) TOP2 $\alpha$ are markedly overexpressed in the cancer tissue compared to the non-cancerous tissue in cases with breast cancer.

associated with various clinicopathological characteristics or with the prediction of poor prognosis in breast cancer patients, and 2) the cases with negative TOP1/TOP $2 \alpha$ had no recurrent disease. Our results suggest that TOP $1 / \mathrm{TOP} 2 \alpha$ expression may be an indicator of disease recurrence in cases with operable $\mathrm{BC}$, and cases with negative TOP1/TOP2 may have a lower risk of disease recurrence. In some types of cancers, elevated TOP1 and TOP $2 \alpha$ expressions were significantly associated with poor survival (7), which is consistent with our present findings.

Elevated expression of TOP1 and TOP $2 \alpha$ is used as a potent biomarker for the response to chemotherapy drugs in multiple cancers. In BC, TOP $2 \alpha$ is well known as a biomarker of anthracyclines treatment, which are some of the most widely used chemotherapeutic agents for BC. However, the evidence of a prognostic role of TOP $2 \alpha$ in BC is controversial $(14,15)$, as is that for TOP1 $(18,19)$. The topology of DNA is regulated by both TOP1 and TOP $2 \alpha$.

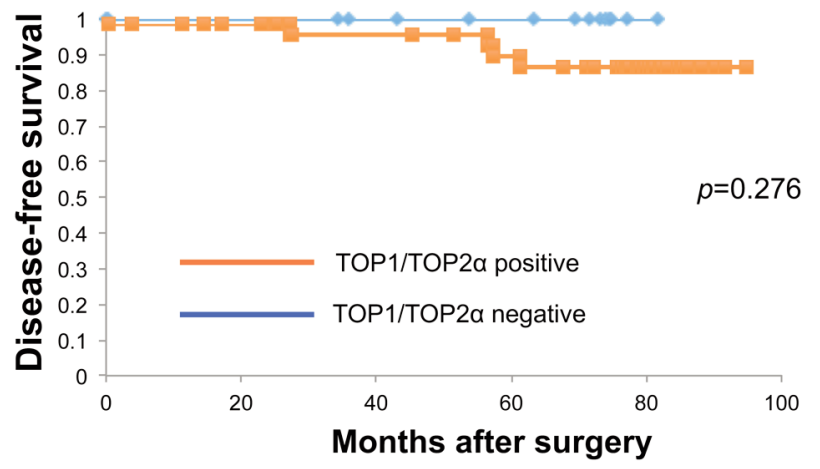

Figure 2. The disease-free survival (DFS) shown by the Kaplan-Meier curves is relatively but not significantly shorter for the cases with positive TOP1/TOP $2 \alpha(p=0.276)$. Among the negative TOP $1 /$ TOP $2 \alpha$ cases, there was no recurrent disease. The overall median follow-up period was 73.1 months (range=3.2-90.0 months).

We, thus, assessed the value of the combination of TOP1 and TOP $2 \alpha$ in this study, and our analyses revealed that there was no recurrence of disease when either TOP 1 or TOP $2 \alpha$ expression was negative. Therefore, an elevated expression of either TOP1 or TOP $2 \alpha$ may not reflect an increased risk for recurrent disease in cases with $\mathrm{BC}$.

The DNA topoisomerases TOP1 and TOP $2 \alpha$ regulate the topology of DNA in cancer tissue and normal tissue (5). Herein, we focused on the differential expressions between tumor tissue and non-tumor tissue. The gene expression ratio of cancerous tissue to non-cancerous tissue from the same case provides more information and reduces the effects of individuality (20). Gene expressions in cancer tissue alone may be insufficient for indicating clinicopathological features. In fact, several comparisons of gene expression profiling between cancer tissue and paired normal tissue have suggested that the gene expression ratio of cancer and normal tissue predicts clinical outcome more efficiently (20-22).

This study has some potential limitations, the major ones is that it is a retrospective analysis with a relatively small number of cases. However, to the best of our knowledge, this is the first report to describe TOP 1 and TOP $2 \alpha$ expression focused on the ratios of tumor $v s$. non-tumorous tissue in cases with $\mathrm{BC}$. The expression rate may provide more information even with small numbers of patients. The negative TOP1/TOP $2 \alpha$ status in breast cancer patients may be predictor of a lower risk of disease recurrence. Additional research is needed to explore possible benefits of determining the TPO1 and TOP $2 \alpha$ expression of primary BC.

In conclusion, the results of our present analyses demonstrated that negative TOP 1 or TOP $2 \alpha$ expression in primary $\mathrm{BC}$ may be effective for predicting better prognoses among cases with $\mathrm{BC}$, and this finding could be useful in identifying the subset of cases with negative TOP $1 / \mathrm{TOP} 2 \alpha$ 
expression for the purpose of improving prognostic accuracy. Large studies are warranted to further evaluate the relationship between the combination of these two factors and $\mathrm{BC}$ recurrence.

\section{Conflicts of Interest}

The Authors declare that they have no competing interests in relation to this study.

\section{Authors' Contributions}

MO and TF analyzed data and TF wrote the initial draft of the manuscript. YN, TH, YK, TO and JH collected data and were involved in the initial study conception and design. TF and KS interpreted the results and were involved in drafting the work and revising it critically for important intellectual content. TF approved the final version to be published. All Authors have read and approved the final manuscript.

\section{Acknowledgements}

The Authors would like to thank Ms. Fumie Takada and Ms. Harumi Kanai for their secretarial assistance. FT and HK belong to Department of General Surgical Science, Gunma University, Maebashi, Japan.

\section{References}

1 Bray F, Ferlay J, Soerjomataram I, Siegel RL, Torre LA and Jemal A: Global cancer statistics 2018: GLOBOCAN estimates of incidence and mortality worldwide for 36 cancers in 185 counties. CA Cancer J Clin 68(6): 394-424, 2018. PMID: 30207593. DOI: $10.3322 /$ caac. 21492

2 Ferlay J, Soerjomataram I, Dikshit R, Eser S, Mathers C, Rebelo M, Parkin DM, Forman D and Bray F: Cancer incidence and mortality worldwide: sources, methods and major patterns in GLOBOCAN 2012. Int J Cancer 136(5): E359-386, 2015. PMID: 25220842. DOI: 10.1002/ijc.29210

3 An X, Xu F, Luo R, Zheng Q, Lu J, Yang Y, Qin T, Yuan Z, Shi $\mathrm{Y}$, Jiang $\mathrm{W}$ and Wang $\mathrm{S}$ : The prognostic significance of topoisomerase II alpha protein in early stage luminal breast cancer. BMC Cancer 18(1): 331, 2018. PMID: 29587760. DOI: 10.1186/s 12885-018-4170-7

4 Ignatiadis $\mathrm{M}$ and Sotiriou $\mathrm{C}$ : Luminal breast cancer: from biology to treatment. Nat Rev Clin Oncol 10(9): 494-506, 2013. PMID: 23881035. DOI: 10.1038/nrclinonc.2013.124

5 Bush NG, Evans-Roberts $\mathrm{K}$ and Maxwell A: DNA topoisomerases. EcoSal Plus 6(2), 2015. PMID: 26435256. DOI: 10.1128/ecosalplus.ESP-0010-2014

6 Heck MM, Hittelman WN and Earnshaw WC: Differential expression of DNA topoisomerases I and II during the eukaryotic cell cycle. Proc Natl Acad Sci USA 85(4): 10861090, 1988. PMID: 2829215. DOI: 10.1073/pnas.85.4.1086

7 Heestand GM, Schwaederle M, Gatalica Z, Arguello D and Kurzrock R: Topoisomerase expression and amplification in solid tumours: analysis of 24,262 patients. Eur J Cancer 83: 8087, 2017. PMID: 28728050. DOI: 10.1016/j.ejca.2017.06.019
8 Liu LM, Xiong DD, Lin P, Yang H, Dang YW and Chen G: DNA topoisomerase 1 and $2 \mathrm{~A}$ function as oncogenes in liver cancer and may be direct targets of nitidine chloride. Int J Oncol 53(5): 18971912, 2018. PMID: 30132517. DOI: 10.3892/ijo.2018.4531

9 Kathiravan MK, Kale AN and Nilewar S: Discovery and development of topoisomerase inhibitors as anticancer agents. Mini Rev Med Chem 16(15): 1219-1229, 2016. PMID: 27549098. DOI: $10.2174 / 1389557516666160822110819$

10 Di Leo A and Isola J: Topoisomerase II alpha as a marker predicting the efficacy of anthracyclines in breast cancer: are we at the end of the beginning? Clin Breast Cancer 4(3): 179-186, 2003. PMID: 14499010.

11 Di Leo, A Desmedt C, Bartlett JM, Piette F, Ejlertsen B, Pritchard KI, Larsimont D, Poole C, Isola J, Earl H, Mourdsen H, O'malley FP, Cardoso F, Tanner M, Munro A, Twelves CJ, Sotiriou C, Shepherd L, Cameron D, Piccart MJ, Buyse M and HER2/TOP2A Meta-analysis Study Group: HER2 and TOP2A as predictive markers for anthracycline-containing chemotherapy regimens as adjuvant treatment of breast cancer: a meta-analysis of individual patient data. Lancet Oncol 12(12): 1134-1142, 2011. PMID: 21917518. DOI: 10.1016/S1470-2045(11)70231-5

12 Hellemans P, van Dam PA, Geyskens M, van Oosterom AT, Buytaert P and van Marck E: Immunohistochemical study of topoisomerase II-alpha expression in primary ductal carcinoma of the breast. J Clin Pathol 48(2): 147-150, 1995. PMID: 7745115. DOI: $10.1136 /$ jcp.48.2.147

13 Coon JS, Marcus E, Gupta-Burt S, Seelig S, Jacobson K, Chen S, Renta V, Fronda G and Preisler HD: Amplification and overexpression of topoisomerase II alpha predict response to anthracycline-based therapy in locally advanced breast cancer. Clin Cancer Res 8(4): 1061-1067, 2002. PMID: 11948114.

14 Shigematsu H, Ozaki S, Yasui D, Yamamoto H, Zaitsu J, Taniyama D, Saitou A, Kuraoka K, Hirata T and Taniyama K: Overexpression of topoisomerase II alpha protein is a factor for poor prognosis in patients with luminal B breast cancer. Oncotarget 9(42): 26701-26710, 2018. PMID: 29928479. DOI: 10.18632/oncotarget.25468

15 Du Y, Zhou Q, Yin W, Zhou L, Di G, Shen Z, Shao Z and Lu J: The role of topoisomerase Ii $\alpha$ in predicting sensitivity to anthracyclines in breast cancer patients: a meta-analysis of published literatures. Breast Cancer Res Treat 129(3): 839-848, 2011. PMID: 21809115. DOI: 10.1007/s10549-011-1694-9

16 Obayashi S, Horiguchi J, Higuchi T, Katayama A, Handa T, Altan B, Bai T, Bao P, Bao H, Yokobori T, Nishiyama M, Oyama $\mathrm{T}$ and Kuwano H: Stathmin 1 expression is associated with aggressive phenotypes and cancer stem cell marker expression in breast cancer patients. Int J Oncol 51(3): 781-790, 2017. PMID: 28766688. DOI: 10.3892/ijo.2017.4085

17 Nakazawa Y, Nakazawa S, Kurozumi S, Ogino M, Koibuchi Y, Odawara H, Oyama T, Horiguchi J, Fujii T and Shirabe K: The pathological complete response and secreted protein acidic and rich in cysteine expression in patients with breast cancer receiving neoadjuvant nab-paclitaxel chemotherapy. Oncol Lett 19(4): 27052712, 2020. PMID: 32218821. DOI: 10.3892/ol.2020.11354

18 Larsen AK and Gobert C: DNA topoisomerase I in oncology: Dr Jekyll or Mr Hyde? Pathol Oncol Res 5(3): 171-178, 1999. PMID: 10491013. DOI: 10.1053/paor.1999.0209

19 Kümler I, Balslev E, Stenvang J, Brünner N, Ejlertsen B, Jakobsen EH and Nielsen DL: Two open-label, single arm, nonrandomized phase II studies of irinotecan for the treatment of 
metastatic breast cancer in patients with increased copy number of the topoisomerase I gene. BMC Cancer 19(1): 573, 2019. PMID: 31196001. DOI: 10.1186/s12885-019-5788-9

20 Ishibashi Y, Hanyu N, Nakada K, Suzuki Y, Yamamoto T, Yanaga K, Ohkawa K, Hashimoto N, Nakajima T, Saito H, Matsushima $\mathrm{M}$ and Urashima M: Profiling gene expression ratios of paired cancerous and normal tissue predicts relapse of esophageal squamous cell carcinoma. Cancer Res 63(16): 51595164, 2003. PMID: 12941848.

21 Xu XR, Huang J, Xu ZG, Qian BZ, Zhu ZD, Yan Q, Cai T, Zhang X, Xiao HS, Qu J, Liu F, Huang QH, Cheng ZH, Li NG, Du JJ, Hu W, Shen KT, Lu G, Fu G, Zhong M, Xu SH, Gu WY, Huang W, Zhao XT, Hu GX, Gu JR, Chen Z and Han ZG: Insight into hepatocellular carcinogenesis at transcriptome level by comparing gene expression profile of hepatocellular carcinoma with those of corresponding noncancerous liver. Proc Natl Acad Sci USA 18(26): 15089-15094, 2001. PMID: 11752456. DOI: $10.1073 /$ pnas.241522398
22 Moustafa AE, Alaoui-Jamali MA, Batist G, Hernandez-Perez M, Serruya C, Alpert L, Black MJ, Sladek R and Foulkes WD: Identification of genes associated with head and neck carcinogenesis by cDNA microarray comparison between matched primary normal and squamous carcinoma cells. Oncogene 21(17): 2634-2640, 2002. PMID: 11965536. DOI: 10.1038/sj.onc.1205351
Received July 7, 2020

Revised July 28, 2020

Accepted July 29, 2020 